\title{
HIV testing and antiretroviral therapy initiation at birth: Views from a primary care setting in Khayelitsha
}

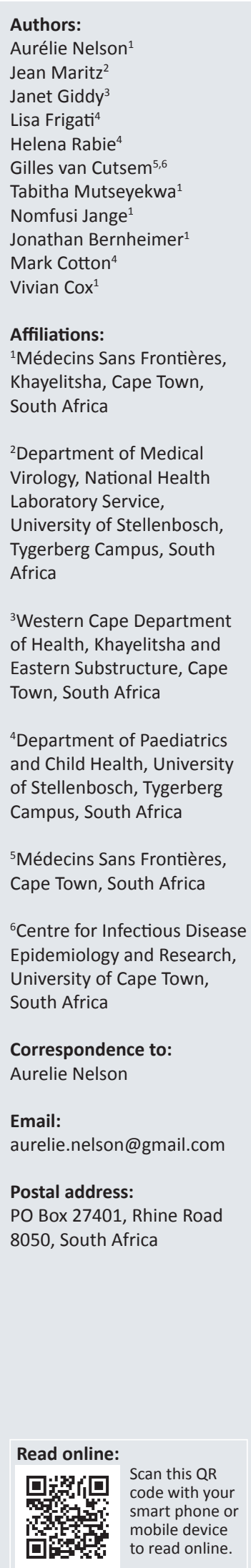

Authors:

Gilles van Cutsem ${ }^{5,6}$

Tabitha Mutseyekwa

Mark Cotton

Khayelitsha, Cape Town,

South Africa

2Department of Medical

Tygerberg Campus, South

${ }^{3}$ Western Cape Department of Health, Khayelitsha and Eastern Substructure, Cape Town, South Africa and Child Health, University of Stellenbosch, Tygerberg

${ }^{5}$ Médecins Sans Frontières, Cape Town, South Africa

${ }^{6}$ Centre for Infectious Disease Epidemiology and Research, University of Cape Town

Correspondence to:

Aurelie Nelson

Email:

Postal address:

PO Box 27401, Rhine Road

8050, South Africa

to read online.

\section{Background}

Despite 95\% coverage via the prevention-of-mother-to-child-transmission (PMTCT) programme, 14000 children in South Africa became HIV-infected in 2012. ${ }^{1}$ There are many reasons for this gap in PMTCT efforts. Late maternal diagnosis of HIV, late antenatal antiretroviral therapy (ART) initiation, seroconversion in pregnancy, and inadequate adherence to ART during gestation singly and collectively increase the risk of transmission. Early initiation of ART in the first few weeks of life significantly reduces the HIV-associated morbidity and mortality in HIV-infected infants, compared with deferred initiation ${ }^{2,3}$ and may reduce the latent HIV-1 reservoir in children. ${ }^{4}$ Furthermore, a recent South African study documents that $76 \%$ of babies who would have tested HIV positive via polymerase chain reaction (PCR) by 6 weeks could have been diagnosed at birth. ${ }^{5}$ Therefore, the Western Cape Province (WCP) Department of Health adopted new guidelines ${ }^{6}$ in June 2014 (and the South African Department of Health in December 201477) to test 'high-risk' infants at birth. Infants testing PCR-positive are started on ART as soon as possible.

In March 2014, Médecins Sans Frontières, in collaboration with the University of Stellenbosch, started a pilot project in a community healthcare centre in Khayelitsha to establish the impact of very early infant diagnosis on ART initiation and to establish the feasibility of implementation in a primary care setting. To establish routine testing of high-risk HIV-exposed infants at the primary care level, the following steps were taken:

- training and mentorship of healthcare staff at the healthcare centre (midwives, nurses, doctors, counsellors) on the new guideline recommendations; the identification and management of high-risk infants; and the clinical management of ART initiation in a newborn

- routine counselling and consent from mothers for birth PCR testing

- initiation of nevirapine (NVP) and zidovudine (AZT) post-exposure prophylaxis on day one in high-risk infants

- PCR and confirmatory viral load testing via the routine courier system to the referring National Health Laboratory Service (NHLS) laboratory, with results available within 48 hours

- counselling all mothers regarding the PCR results at 48 hours of life, when the mother and infant return to the health centre for routine post natal care:

- if the PCR result is negative, the mother is advised of the necessity to keep the infant in care for repeat HIV testing as per WCP guidelines as well as to continue post-exposure prophylaxis

- if the infant is HIV positive, the nurse caring for the mother/infant pair provides standardised ART initiation counselling and ensures the infant is seen by a medical officer the same day

- initiation of ART on the same day as diagnosis for clinically well infants, according to interim infant ART treatment guidelines developed in consultation with infectious disease paediatricians, and referral to the district hospital for clinically unwell infants

- close follow-up of the infants on ART: weekly until 6 weeks of age and monthly until 2 years of age, including routine monitoring bloods and a repeat viral load at 4 months of age

- monitoring of further HIV test results in HIV-exposed infants testing negative at birth, to identify further HIV-positive infants and to assess the coverage of HIV testing per guidelines to 18 months of age.

Dates: Received: 23 Feb. 2015 | Accepted: 17 Mar. 2015 | Published: 28 Apr. 2015

How to cite this article: Nelson A, Maritz J, Giddy J, et al. HIV testing and antiretroviral therapy initiation at birth: Views from a primary care setting in Khayelitsha. S Afr J HIV Med. 2015;16(1), Art. \#376, 4 pages. http://dx.doi.org/10.4102/sajhivmed.v16i1.376

Copyright: @ 2015. The Authors. Licensee: AOSIS OpenJournals. This work is licensed under the Creative Commons Attribution License. 
TABLE 1: Demographics and early outcomes of three HIV-positive infants diagnosed at birth in a primary care setting.

\begin{tabular}{|c|c|c|c|}
\hline Demographics and outcomes & Case 1 & Case 2 & Case 3 \\
\hline \multirow[t]{2}{*}{ Antenatal risk factors for transmission } & $\begin{array}{l}\text { Mother unbooked in labour (mother } \\
\text { known ART treatment interrupter) }\end{array}$ & $\begin{array}{l}\text { ART }<12 \text { weeks in pregnancy (late } \\
\text { booking at } 25 \text { weeks [HIV negative] } \\
\text { and seroconverted at } 32 \text { weeks) }\end{array}$ & $\begin{array}{l}\text { ART }<12 \text { weeks in pregnancy (late } \\
\text { booking at } 31 \text { weeks) }\end{array}$ \\
\hline & - & - & $\begin{array}{l}\text { Infant born prematurely at } 36 \text { weeks' } \\
\text { gestation }\end{array}$ \\
\hline \multirow[t]{2}{*}{ Mother's results } & Viral load ( 2 weeks after delivery): 484 & Viral load ( 2 weeks after delivery): 302 & Viral load not available \\
\hline & CD4 162 on day of delivery & CD4 281 at 32 weeks & CD4 293 at booking at 31 weeks \\
\hline Time from birth to ART initiation & 16 days & 2.5 days & 2 days \\
\hline WHO stage at initiation & Stage 2 & Stage 1 & Stage 1 \\
\hline \multirow[t]{5}{*}{ Challenges at initiation } & Fear of disclosure and stigma & Low socio-economic status & Low socio-economic status \\
\hline & Distrust of healthcare system & Financially dependent on partner & No stable relationship \\
\hline & Poor social support & - & - \\
\hline & Low socio-economic status & - & - \\
\hline & Financially dependent on partner & - & - \\
\hline Viral load (copies/mL) & 871740 & 1015 & $\begin{array}{l}\text { Lower than detectable (LDL) (repeat at } \\
10 \text { days of life-on ART: 265) }\end{array}$ \\
\hline $\begin{array}{l}\text { CD4 cell count (percentage of total } \\
\text { lymphocytes) }\end{array}$ & $1731(34 \%)$ & $2082(27 \%)$ & $1364(66 \%)$ \\
\hline HIV drug resistance testing & No resistance & $\begin{array}{l}\text { Amplification not possible owing to low } \\
\text { viral load }\end{array}$ & $\begin{array}{l}\text { Amplification not possible owing to low } \\
\text { viral load }\end{array}$ \\
\hline Feeding method & Formula feeding & $\begin{array}{l}\text { Reverted to breast feeding when infant } \\
\text { initiated ART }\end{array}$ & $\begin{array}{l}\text { Reverted to breast feeding when infant } \\
\text { initiated ART }\end{array}$ \\
\hline First ART regimen & $\mathrm{AZT} / 3 \mathrm{TC} / \mathrm{NVP}$ & $\mathrm{AZT} / 3 \mathrm{TC} / \mathrm{NVP}$ & AZT/3TC/NVP \\
\hline $\begin{array}{l}\text { Second ART regimen: NVP replaced } \\
\text { with } L P V / r\end{array}$ & $\begin{array}{l}3 \text { weeks of age (gestational age } \\
\text { unknown) }\end{array}$ & $\begin{array}{l}2 \text { weeks of age (gestational age } \\
\text { unknown) }\end{array}$ & $\begin{array}{l}6 \text { weeks of age ( } 42 \text { weeks' gestational } \\
\text { age) }\end{array}$ \\
\hline \multirow[t]{2}{*}{ Prophylactic medications } & $\begin{array}{l}\text { Co-trimoxazole (started at } 4 \text { weeks } \\
\text { of age) }\end{array}$ & $\begin{array}{l}\text { Co-trimoxazole (started at } 4 \text { weeks } \\
\text { of age) }\end{array}$ & $\begin{array}{l}\text { Co-trimoxazole (started at } 4 \text { weeks } \\
\text { of age) }\end{array}$ \\
\hline & Isoniazid (INH) for 6 months & - & - \\
\hline \multirow[t]{2}{*}{ Viral load (copies $/ \mathrm{mL}$ ) at 4 months $\dagger$} & 1823 & $<40$ (month 3 ) & $<40$ \\
\hline & - & $A Z T$ replaced by $A B C$ & $A Z T$ replaced by $A B C$ \\
\hline Mother VL 3-4 months after delivery & $<40$ & $<40$ & $<40$ \\
\hline Adverse events & $\begin{array}{l}\text { Hospitalised for bronchiolitis and to } \\
\text { exclude TB (owing to presumed TB } \\
\text { contact). Completed } 6 \text { months of INH. }\end{array}$ & Mild anaemia (Hb 10.4) & $\begin{array}{l}\text { Hospitalised for initial high ALT at ART } \\
\text { initiation (probably lab error). Repeat } \\
\text { was normal. }\end{array}$ \\
\hline \multirow[t]{2}{*}{ Other challenges encountered } & $\begin{array}{l}\text { Transient migration to Eastern Cape } \\
\text { over holiday period }\end{array}$ & $\begin{array}{l}\text { Initial mix-up with ARV dosage despite } \\
\text { extensive counselling }\end{array}$ & $\begin{array}{l}\text { Mother claimed to be ART naïve at } \\
\text { booking }\end{array}$ \\
\hline & - & $\begin{array}{l}\text { Transient migration to Eastern Cape over } \\
\text { holiday period }\end{array}$ & - \\
\hline
\end{tabular}

$\dagger$, Viral load recommended at 4 months after ART initiation as per Western Cape Government Department of Health prevention-of-mother-to-child-transmission clinical guidelines update. ${ }^{6}$ ART, antiretroviral therapy; NVP, nevirapine; AZT, zidovudine; INH, Isoniazid.

By the end of December 2014, we had identified 138 high-risk infants delivered at the primary healthcare centre and we tested 132 high-risk infants (95\% of highrisk infants delivered at the centre had a birth PCR) of whom 3 had a positive HIV PCR. The 3 cases are summarised in Table 1 and the lessons learnt from them are described below.

\section{Cases of positive HIV polymerase chain reaction: Lessons learnt}

\section{Case 1}

Case 1 was complicated by a mother struggling with numerous psychosocial difficulties: low socioeconomic status, fear of stigmatisation and of disclosure to her partner/family, and deep mistrust of the healthcare system. Despite repeated attempts to contact her, she only returned to care when the infant was 9 days old after her perception of her baby being healthy changed after the infant developed conjunctivitis. This case was a good illustration of how barriers at the individual level (low socioeconomic background and psychological factors such as fear of disclosure and stigma) can prevent access to ART for the infant. $^{8}$ By addressing these barriers through individual counselling by healthcare providers and peer support from an organisation experienced in supporting HIV-positive mothers, the mother and infant returned to care and have remained in care to date (10 months later). They are both showing good adherence and viral suppression.

\section{Case 2}

Case 2 confirmed the higher risk of transmission with a presumed HIV incident infection in the mother, as reported in other studies such as that by Drake et al. ${ }^{9}$ Good support and counselling allowed the mother to overcome her initial shock and to accept the need to initiate her infant on ART. She and her baby are suppressed and doing very well. 


\section{Case 3}

Case 3 illustrates the importance of early booking as intrauterine HIV transmission to the infant could have been prevented if the mother had been diagnosed and started on ART earlier in the pregnancy. In this instance, too, extensive support and counselling assisted the mother in accepting the diagnosis and starting treatment for the infant. Both are now virologically suppressed.

So far, we have demonstrated that testing high-risk infants at birth is possible in a primary care setting, with 129 out of 130 mothers eager for their infants to be tested at birth (other high-risk infants were not tested for other reasons such as already being enrolled in another study, mother missed, etc.). Although concerns were expressed by healthcare providers and counsellors on the psychosocial readiness of the mothers to initiate ART, we found that it was possible and sustainable, with structured ART initiation counselling and adherence support. ART programmes aimed at the implementation of early infant diagnosis strategies should consider modification of the existing three pre-ART routine counselling sessions as essential, given the timing of ART initiation in newborns and the early challenges that both mother and infant are likely to experience in the first months on ART.

Prior to starting the pilot study, we had concerns about the timing of sample transport from the primary care setting to the central laboratory. In fact, the average turnaround time for PCR results has been 48 hours, allowing prompt initiation of babies on ART after birth. Programmatically, it may be more difficult in rural areas, where there may be a longer turnaround time to obtain results. Furthermore, in our pilot project, about $22 \%$ of women did not come back for the results of the baby's birth PCR. Using a point of care (POC) PCR machine at birth, with good sensitivity and specificity, could reduce the attrition of patients not returning for results and improve early management of HIV-exposed infants. More research is needed to look into which POC platform would be optimal and the feasibility of its use at a primary care level.

ART initiation in this pilot project was undertaken by a general medical officer in a primary care setting, with the telephonic support of infectious disease paediatricians. As described in an article by Nuttall ${ }^{10}$ in the present issue of the Southern African Journal of HIV Medicine, initiating ART in a neonate is more intricate than for a 6-week-old infant in terms of available drugs, dosage and monitoring. An initial lack of confidence to initiate neonates on ART was observed during the mentorship of primary care medical officers, mostly related to lack of experience in calculating paediatric dosages and in blood draws in neonates. With the guidance of infectious disease paediatricians at our tertiary referral centre, we designed an interim guide on ART initiation at birth where we attempted to simplify blood tests for monitoring and the calculation of dosages. Modelled on existing ART drug dosing charts, the guide reduces the complexity of neonatal ART initiation and thus increases the confidence of clinicians managing well infants on ART at primary care level.

In addition to being well received by primary care doctors, mentorship on primary care ART initiation for stable infants was well received by the local district hospital, as it reduces the burden on their overstretched services. Furthermore, from the patient's point of view, previous studies show that accessing local clinics rather than distant referral hospitals leads to better retention in care, ${ }^{8,11}$ which is what we experienced on the ground, with the above three patients' mothers being compliant with their appointments. The mother builds a trusting relationship with one or two health workers, which probably additionally promotes her retention in care. As we observed, assisting the very vulnerable mother-infant pair through the initial phase of ART may greatly assist long-term compliance with clinic visits.

The major difficulty encountered with ART initiation was for the mother to understand the dosage of syrups appropriately, particularly with the high number of changes in the first few months of treatment. This finding is corroborated by other MSF projects in which paediatric treatment failure has been linked directly to under-dosage by the caregiver (internal source). To overcome this difficulty, sufficient time must be spent counselling the mother on how to administer syrups; visual methods on how much of each syrup to give (using colour stickers and marked syringes) can be very helpful for mothers to understand the measurements. Assigning specific responsibility to the pharmacist, counsellor, nurse or doctor for this education on medication dosing is crucial for ART initiation in neonates to be rolled out effectively in a primary care setting.

Finally, whilst following up the birth PCR-negative babies, we observed that most women take their infants for a '6-weeks PCR' but very few of them actually come to clinics in the right time frame (6-8 weeks). Most of the '6-weeks PCR' tests are done at random times, showing that mothers return to clinics when it suits them, not when they are given a date. Further studies are needed to evaluate the impact of this observation as well as the reasons behind it, and how to adapt the existing system to the needs and demands of new mothers.

\section{Conclusion}

We started a pilot project in a primary care centre in Khayelitsha in March 2014 to establish the impact of very early infant diagnosis in reducing the age at ART initiation, and to investigate the feasibility of implementing both early diagnosis and early ART initiation in a primary care setting. So far, we have diagnosed 3 HIV-positive infants out of 129 high-risk HIV-exposed babies tested, and all 3 babies were initiated on ART from 2 days to 2.5 weeks after birth. They are currently doing well: all 3 infants are adherent to their medication and are virologically suppressed on ART. Overall, we have established the feasibility of testing newborns for HIV at birth and initiating ART in the first days 
of life in a primary care setting with appropriate mentorship of healthcare providers and consistent adherence support for mothers. By promoting a decentralised model of early infant diagnosis at birth, programmes will ensure access to care for some of the most vulnerable patients with HIV infection.

\section{Acknowledgements Competing interests}

The authors declare that they have no financial or personal relationships which may have inappropriately influenced them in writing this article.

\section{Authors' contributions}

A.N. (Médecins Sans Frontières) contributed to the conception, design, data acquisition, interpretation, and co-drafting of the paper. J.M. (University of Stellenbosch) drafted the ethics protocol and contributed to the conception, intervention implementation and critical review of the paper. J.G. (Western Cape Department of Health) contributed to the critical review of the paper. L.F. (University of Stellenbosch) contributed to the intervention implementation and critical review of the paper. H.R. (University of Stellenbosch) contributed to the intervention implementation and critical review of the paper. G.v.C. (Médecins Sans Frontières) contributed to the conception and critical review of the paper. T.M. (Médecins Sans Frontières) contributed to the intervention implementation and critical review of the paper. N.J. (Médecins Sans Frontières) contributed to the intervention implementation and critical review of the paper.
J.B. (Médecins Sans Frontières) contributed to the critical review of the paper. M.C. (University of Stellenbosch) contributed to the intervention implementation and critical review of the paper. V.C. (Médecins Sans Frontières) contributed to the conception, design and co-drafting of the paper and approved it for publication.

\section{References}

1. Evaluation of the effectiveness of the national PMTCT programme measured at six weeks postpartum in South Africa. Durban: SAPMTCTE study group, MRC, NDOH \&PEPFAR/US Centers for Disease Control and Prevention; 2012

2. Violari A, Cotton MF, Gibb DM, et al. Early antiretroviraltherapy and mortality among HIV-infected infants. N Engl J Med. 2008;359:2233-2244. http://dx.doi. org/10.1056/NEJMoa0800971

3. Wamalwa $D$, Benki-Nugent $S$, Langat $A$, et al. Survival benefit of early infant antiretroviral therapy is compromised when diagnosis is delayed. Pediatr Infect Dis J. 2012;31:729-731. http://dx.doi.org/10.1097/INF.0b013e3182587796

4. Persaud D, Palumbo PE, Ziemniak C, et al. Dynamics of the resting CD4(+) T-cell latent HIV reservoir in infants initiating HAART less than 6 months of age. AIDS 2012;26:1483-1490. http://dx.doi.org/10.1097/QAD.0b013e3283553638

5. Lilian RR, Kalk E, Technau KG, Sherman GG. Birth diagnosis of HIV infection in infants to reduce infant mortality and monitor for elimination of mother-to-child transmission. Pediatr Infect Dis J. 2013;32:1080-1085. http://dx.doi.org/10.1097/ INF.0b013e318290622e

6. Western Cape Government Department of Health PMTCT clinical guidelines update. Cape Town: Western Cape Department of Health; June 2014.

7. National consolidated guidelines for the prevention of mother-to-child transmission of HIV (PMTCT) and the management of HIV inchildren, adolescents and adults. Pretoria: National Department of Health; December 2014.

8. Gourlay A, Birdthistle I, Mburu G, lorpenda K, Wringe A. Barriers and facilitating factors to the uptake of antiretroviral drugs for prevention of mother-to-child transmission of HIV in sub-Saharan Africa: A systematic review. J Int AIDS Soc. 2013;16:18588. http://dx.doi.org/10.7448/IAS.16.1.18588

9. Drake A, Wagner A, Richardson B, John-Stewart G. Incident HIV during pregnancy and postpartum and risk of mother-to-child HIV transmission: A systematic review journal.pmed.1001608

10. Nuttall JJC. Antiretroviral therapy during the neonatal period. Southern African Journal of HIV Medicine. In press 2015

11. Scanlon M, Vreeman R. Current strategies for improving access and adherence to antiretroviral therapies in resource-limited settings. HIV AIDS (Auckl). 2013;5:1-17. 